\title{
Group B Streptococcus Risk
}

National Cancer Institute

\section{Source}

National Cancer Institute. Group B Streptococcus Risk. NCI Thesaurus. Code 1111946.

Categ orization for likelihood of perinatal transmission of group B Streptococcus to neonate. 